\title{
Comparison of Different Optimization Criteria for Optimal Sizing of Hybrid Active Power Filters Parameters
}

\author{
K. T. M. Elmathana and Ahmed F. Zobaa \\ ${ }^{1}$ School of Engineering and Design, Brunel University, Uxbridge, UB8 3PH, Middlesex, United Kingdom \\ *Corresponding author email: Khaled.Elmathana@,brunel.ac.uk \\ Fax: 0044-1895 -269782 \\ Phone: 0044-1895-265335
}

\begin{abstract}
Harmonic distortion in power systems has increased considerably due to the increasing use of nonlinear loads in industrial firms and elsewhere. This distortion can give rise to overheating in all sectors of the power system, leading to reduced efficiency, reliability, operational life and sometimes failure. This article seeks to propose a new methodology for the optimal sizing of hybrid active power filter (HPF) parameters in order to overcome the difficulties in hybrid power filters design when estimating the preliminary feasible values of the parameters. Sequential Quadratic Programming based on FORTRAN subroutines is used to find out the planned filter size in two different optimization criteria depending on design concerns. The first criterion is to minimize the total voltage harmonic distortion. The second one is to maximize the load power factor, while taking into account compliance with IEEE standard 519-1992 limits for the total voltage harmonic distortion and the power factor.The effectiveness of the proposed filter is discussed using four exemplary cases.
\end{abstract}

Keywords: Active filters, harmonics distortion, hybrid filters, power quality, power systems harmonics, optimization

Short Running Title: Optimal Hybrid Active Power Filters Design

\section{NOMENCLATURE}

$\mathrm{K}$

$\mathrm{X}_{\mathrm{P}}, \mathrm{X}_{\mathrm{C}}$

$V_{\mathrm{n}}$

$\mathrm{I}_{\mathrm{Sn}}$

ITHD

$\mathrm{I}_{\mathrm{S}}$

$\mathrm{R}_{\mathrm{Ln}}, \mathrm{X}_{\mathrm{Ln}}$

$\mathrm{R}_{\mathrm{Tn}}, \mathrm{X}_{\mathrm{Tn}}$

$\mathrm{V}_{\mathrm{Sn}}$

$\mathrm{I}_{\mathrm{Ln}}$

$\mathrm{V}_{\mathrm{Ln}}$

$\mathrm{V}_{\mathrm{L}}$

VTHD

$\mathrm{P}_{\mathrm{L}}$

$\mathrm{PF}$

$\mathrm{dPF}$ filter $(\Omega)$ (A)
Controlled Gain of the active filter $(\Omega)$

The fundamental inductive and capacitive reactance of the passive

Controlled voltage source representing the injected voltage-waveform of the active filter at harmonic number $n(\mathrm{~V})$

Supply current at harmonic number $n$

Total harmonic distortion of the supply current (\%)

Rms value of supply current (A)

Load resistance and reactance in ohms

at harmonic number $n(\Omega)$

Thevenin source resistance and reactance at harmonic number $n(\Omega)$

Single-phase supply voltage at harmonic number $n(\mathrm{~V})$

Injected load harmonic current at

harmonic number $n(\mathrm{~A})$

Single-phase load voltage at harmonic number $n(\mathrm{~V})$

Rms value of the load voltage (V)

Total harmonic distortion of the load voltage (\%)

Single-phase load active power (W)

Load power factor (\%)

Displacement power factor (\%)

\section{INTRODUCTION}

Power Quality has been an issue ever since electrical power was made-up. It has only become well-known issue in recent years because of the loads it affects, especially after the rapid growth of nonlinear loads in industrial firms and elsewhere. Over the last few decades, much attention has been focused on power system harmonics. This is one of the most severe issues causing a reduction in power quality. Amplification of harmonic currents and/or voltages can have detrimental effects on other elements of the system. However, the harmonic content of the power system can be reduced by adding harmonic filters (passive and/or active) in the distribution systems [1]-[9].

Passive filters are commonly used in harmonic mitigation and reactive-power compensation because of their straightforwardness and reasonable cost. Conversely, cost of the active filters is comparatively high and they suffer from power-rating difficulties in large-scale power systems [6]. To reduce the system cost; hybrid power filters (HPFs) have been proposed and used [7]-[14].

The hybrid power filter, configured by a power converter and a set of tuned filters, is expected to improve the passive filter compensation characteristics and the resonance (series and/or parallel) problems of the existing passive filters. Roughly speaking, the tuned filters used in the hybrid power filter are to reduce the power capacity of the power converters [13].

In this article, a hybrid active power filter, series-type, 
is proposed as a series grouping of conventional passive facility (single-tuned shunt passive filter) and an active facility. The proposed filter is connected in parallel with the nonlinear load at the point of common coupling (PCC). The hybrid power filter performance is controlled by adjusting its gain value $(\mathrm{K})$ and other filter parameters as the inductive reactance $X_{P}$ and capacitive reactance $X_{C}$ of the passive facility.

From harmonic compensation point of view (usual requirement of the utilities and standards); an optimal sizing of the HPF parameters, is made based on minimization of the total voltage harmonic distortion (VTHD) of linear and nonlinear loads at the (PCC), where maintaining the load power factor $(P F)$ at an acceptable specified range $(90 \leq P F \leq 95 \%)$ is desired.

From power factor correction point of view (usual requirement of the customers, especially to avoid penalties of low power factor); an optimal sizing of the HPF parameters, is made based on maximization of the load power factor, where maintaining the VTHD at an acceptable limit is desired, while taking into account compliance with IEEE Std. 519-1992 [15], [16].

The essential equations required for the HPF design, are identified, also, the robustness and effectiveness of using the proposed filter under various cases of study is demonstrated, furthermore, a detailed comparison of the two optimization criteria used for the optimal design of the HPF are demonstrated, in order to show the capability of the proposed filter in harmonic mitigation for currents, voltages and damping resonance.

\section{HYBRID POWER FILTER CONFIGURATION}

Fig. (1). illustrates the simplified system arrangement of a HPF, where the active filter is connected in series with a single-tuned shunt passive filter. The active filter is controlled as a current-controlled voltage-source system. Recalling [10], the voltage-source converter of the HPF is recognized to suppress harmonic current and enhance the passive facility performance by introducing a voltage-harmonic waveform at its terminals, given as

$\mathrm{V}_{\mathrm{n}}=\mathrm{K} * \mathrm{I}_{\mathrm{Sn}}$

where: $n$ is the harmonic order and $K$ is the gain of controlled voltage- source. It is intended to come to zero at the fundamental frequency $(n=1)$. Adjusting the gain value; prominent decrease in the the total harmonic distortion (ITHD) of the source current will occur, with no hazards of resonance occurrence. If the gain is small, the passive filtering will be dominant and the conventional problems of the passive filter will appear because of the decrease in the hybrid filter bandwidth [13]. On the contrary, larger gain improves the hybrid filter compensation performance and eliminates the resonance possibility between passive filters and source/load impedance. In other words, the power converter will anticipate in the filtering process as a harmonic resistor that is in series with the main supply impedance at the harmonic frequency. Then, the resonance of passive power filters can be suppressed, while mitigating harmonic components and causing a notable reduction in the supply current total harmonic distortion. Besides, the effective harmonic impedance of main supply will increase, and the filter performance will be significantly improved.

Many connections of the passive and the active filters are found in the literature [7], [13], however, the proposed connection of them (in series) is used because it leads to a significant decrease of power-rating of the inverter used. As the the fundamental voltage across the active filter equals zero, i.e. $V_{1}=0$; the inverter has to work aligned with a low voltage. This results in a large voltage rating reduction of the active filter, which is an important benefit of dipping the $k V A$ rating [13].

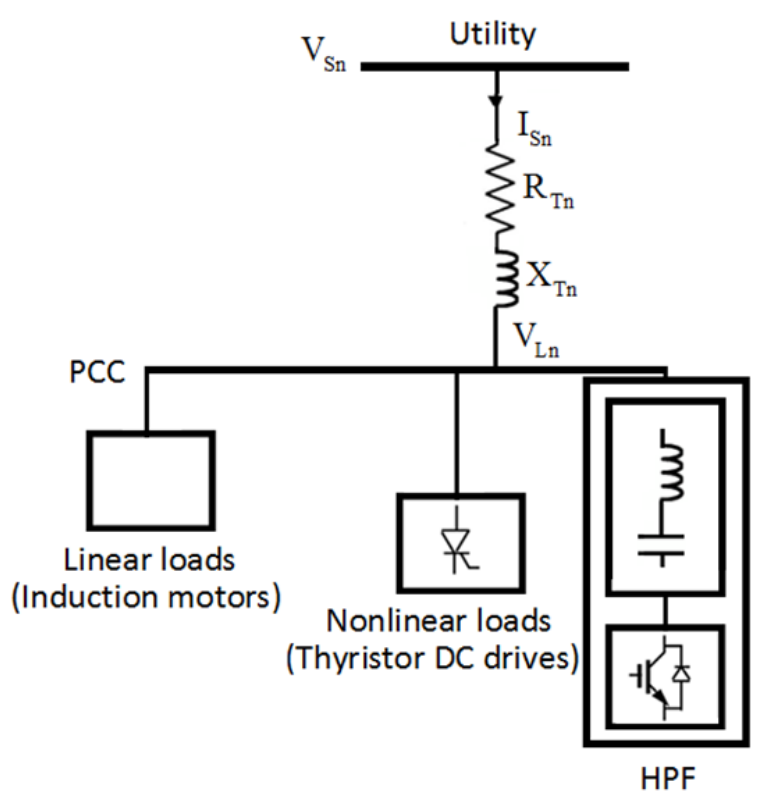

Fig. (1). Single-phase diagram of the proposed arrangement

It must be mentioned that this arrangement can be applied with already installed passive filters, by connecting a series active power filter at its terminals, and controlling the compensation characteristics by the gain adjustment.

\section{COMPENSATED SYSTEM ARRANGEMENT}

Fig. (2). demonstrates the single-phase equivalent circuit of the system configuration under study. Linear loads shown represent a group of induction motors. Also, the nonlinear loads shown are specifically representing thyristors DC drives loads. DC drives are commonly characterized by ideal current source at their characteristic frequencies [17]-[19].

The $n$th harmonic Thevenin source impedance $Z_{\mathrm{Tn}}, n$th harmonic passive filter impedance $Z_{\mathrm{Fn}}$, and the $n$th harmonic load impedance $Z_{\mathrm{Ln}}$ are given as 
$\mathrm{Z}_{\mathrm{Tn}}=\mathrm{R}_{\mathrm{Tn}}+\mathrm{j} \mathrm{X}_{\mathrm{Tn}}$

$\mathrm{Z}_{\mathrm{Ln}}=\mathrm{R}_{\mathrm{Ln}}+\mathrm{j} \mathrm{X}_{\mathrm{Ln}}$

$\mathrm{Z}_{\mathrm{Fn}}=\mathrm{R}_{\mathrm{Fn}}+\mathrm{j} \mathrm{X}_{\mathrm{Fn}} \square \mathrm{j}\left(\mathrm{X}_{\mathrm{Pn}}-\mathrm{X}_{\mathrm{Cn}}\right)=\mathrm{j}\left(\mathrm{n} \mathrm{X}_{\mathrm{P}}-\frac{\mathrm{X}_{\mathrm{C}}}{\mathrm{n}}\right)$

where: $R_{F}$ and $X_{P}$ and $X_{C}$ are the magnitudes of the passive compensator resistance, inductive reactance and capacitive reactance, respectively, all expressed in ohms at the fundamental frequency.

As shown in Equation (4); the internal resistance of the passive inductive reactance is considered as a null resistance, due to its small value with respect to magnitude of its fundamental inductive reactance [17], [19].

Voltage-source nonlinearity is represented in the source harmonic voltages as $V_{\mathrm{Sn}}$. Ref. [19] validates that increase in the supply voltage distortion has a worse influence on filtering characteristics than load current distortion changes. Thus, the background harmonic voltage levels are taken into account in this analysis. Additionally, harmonic current-type nonlinear load is represented in harmonic load currents as $I_{\mathrm{Ln}}$.

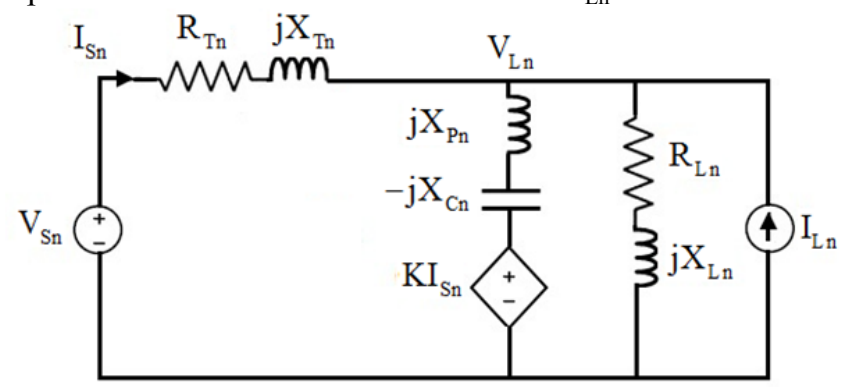

Fig. (2). Single-phase equivalent circuit of the compensated system for $n$th harmonics

\section{PERFORMANCE ANALYSIS}

Recalling Fig. (2), the $n$th harmonic supply current $I_{\mathrm{Sn}}$ is given as

$$
\begin{gathered}
I_{\text {Sn }}=\frac{Z_{\text {Fn }} Z_{\text {Ln }}}{Z_{\text {Sn }} Z_{\text {Fn }}+Z_{\text {Sn }} Z_{\text {Ln }}+Z_{\text {Fn }} Z_{\text {Ln }}+K Z_{\text {Ln }}} I_{\text {Ln }} \\
+\frac{Z_{\text {Fn }}+Z_{\text {Ln }}}{Z_{\text {Sn }} Z_{\text {Fn }}+Z_{\text {Sn }} Z_{L n}+Z_{\text {Fn }} Z_{\text {Ln }}+K Z_{\text {Ln }}} V_{\text {Sn }}
\end{gathered}
$$

Simplifying and arranging; $I_{\mathrm{Sn}}$ is given as

$\mathrm{I}_{\mathrm{Sn}}=\frac{\mathrm{NI}_{\mathrm{R}}+\mathrm{jNI}}{\mathrm{D}_{\mathrm{R}}+\mathrm{j} \mathrm{D}_{\mathrm{I}}}$

The compensated load voltage $\left(V_{\mathrm{Ln}}\right)$ is given as

$\mathrm{V}_{\mathrm{Ln}}=\frac{\mathrm{NV}_{\mathrm{R}}+\mathrm{jNV}}{\mathrm{D}_{\mathrm{R}}+\mathrm{j} \mathrm{D}_{\mathrm{I}}}$

where:

$$
\begin{aligned}
& \mathrm{NI}_{\mathrm{R}}=\mathrm{V}_{\mathrm{Sn}} \mathrm{R}_{\mathrm{Ln}}-\mathrm{I}_{\mathrm{Ln}} \mathrm{X}_{\mathrm{Ln}} \mathrm{X}_{\mathrm{Fn}}, \\
& \mathrm{NI}_{\mathrm{I}}=\mathrm{V}_{\mathrm{Sn}}\left(\mathrm{X}_{\mathrm{Ln}}+\mathrm{X}_{\mathrm{Fn}}\right)+\mathrm{I}_{\mathrm{Ln}} \mathrm{R}_{\mathrm{Ln}} \mathrm{X}_{\mathrm{Fn}}, \\
& \mathrm{NV}_{\mathrm{R}}=\mathrm{V}_{\mathrm{Sn}}\left(\mathrm{KR}_{\mathrm{Ln}}-\mathrm{X}_{\mathrm{Ln}} \mathrm{X}_{\mathrm{Fn}}\right)+\mathrm{I}_{\mathrm{Ln}} \mathrm{X}_{\mathrm{TLn}} \mathrm{X}_{\mathrm{Fn}}, \\
& \mathrm{NV}_{\mathrm{I}}=\mathrm{V}_{\mathrm{Sn}}\left(\mathrm{R}_{\mathrm{Ln}} \mathrm{X}_{\mathrm{Fn}}+\mathrm{KX}_{\mathrm{Ln}}\right)-\mathrm{I}_{\mathrm{Ln}} \mathrm{R}_{\mathrm{TLn}} \mathrm{X}_{\mathrm{Fn}} .
\end{aligned}
$$

$\mathrm{D}_{\mathrm{R}}=\mathrm{R}_{\mathrm{TLn}}+\mathrm{KR}_{\mathrm{Ln}}-\left(\mathrm{X}_{\mathrm{Ln}}+\mathrm{X}_{\mathrm{Tn}}\right) \mathrm{X}_{\mathrm{Fn}}$,

$\mathrm{D}_{\mathrm{I}}=\mathrm{X}_{\mathrm{TLn}}+\mathrm{KX}_{\mathrm{Ln}}+\left(\mathrm{R}_{\mathrm{Ln}}+\mathrm{R}_{\mathrm{Tn}}\right) \mathrm{X}_{\mathrm{Fn}}$,

So that:

$\mathrm{R}_{\mathrm{TLn}}=\mathrm{R}_{\mathrm{Tn}} \mathrm{R}_{\mathrm{Ln}}-\mathrm{X}_{\mathrm{Ln}} \mathrm{X}_{\mathrm{Tn}}$ and $\mathrm{X}_{\mathrm{TLn}}=\mathrm{R}_{\mathrm{Ln}} \mathrm{X}_{\mathrm{Tn}}+\mathrm{R}_{\mathrm{Tn}} \mathrm{X}_{\mathrm{Ln}}$.

Hence, the rms values of the supply current and the load voltage are given as

$\mathrm{I}_{\mathrm{S}}=\sqrt{\sum_{\mathrm{n}} \mathrm{I}_{\mathrm{Sn}}^{2}}$
$\mathrm{~V}_{\mathrm{L}}=\sqrt{\sum_{\mathrm{n}} \mathrm{V}_{\mathrm{Ln}}^{2}}$

The first term on the right side of (5) means that the HPF acts as a "damping resistor," which can entirely attenuate the parallel resonance between the shunt passive filter and the source impedance.

The ratio of the source harmonic current to the load current under the assumption of $V_{\mathrm{Sn}}$ equals zero is given in Equation (10). The amplitude of (10) is called "attenuation factor, AF".

$$
\mathrm{AF}=\left|\frac{\mathrm{I}_{\mathrm{Sn}}}{\mathrm{I}_{\mathrm{Ln}}}\right| \underset{\mathrm{V}_{\mathrm{Sn}}=0}{\downarrow}=\left|\frac{\mathrm{Z}_{\mathrm{Fn}} \mathrm{Z}_{\mathrm{Ln}}}{\mathrm{Z}_{\mathrm{Sn}} \mathrm{Z}_{\mathrm{Fn}}+\mathrm{Z}_{\mathrm{Sn}} \mathrm{Z}_{\mathrm{Ln}}+\mathrm{Z}_{\mathrm{Fn}} \mathrm{Z}_{\mathrm{Ln}}+\mathrm{KZ} Z_{\mathrm{Ln}}}\right|
$$

The second term on the right side of (5) means that the HPF acts as an "obstructing resistor," which can obstruct the harmonic current produced by $V_{\mathrm{Sn}}$ from flowing into the shunt passive filter [11]. Under the assumption of $I_{\mathrm{Ln}}$ equals zero; the current harmonic distortion will occur due to $V_{\mathrm{Sn}}$. This current is given as shown below in (11).

$\left|\frac{\mathrm{I}_{\mathrm{Sn}}}{\mathrm{V}_{\mathrm{Sn}}}\right| \underset{\mathrm{I}_{\mathrm{Ln}}=0}{\downarrow}=\frac{1}{\mathrm{Z}}=\left|\frac{\left(\mathrm{Z}_{\mathrm{Fn}}+\mathrm{Z}_{\mathrm{Ln}}\right)}{\left(\mathrm{Z}_{\mathrm{Sn}} \mathrm{Z}_{\mathrm{Fn}}+\mathrm{Z}_{\mathrm{Sn}} \mathrm{Z}_{\mathrm{Ln}}+\mathrm{Z}_{\mathrm{Fn}} \mathrm{Z}_{\mathrm{Ln}}+\mathrm{KZ}_{\mathrm{Ln}}\right)}\right|$

Assuming the rated impedance, based on rated voltage $V_{R}$ and rated current $I_{R}$, equals $Z_{R}$; the ratio of $\left|Z / Z_{R}\right|$ indicates whether the passive filter falls in series resonance with the mains or not. The active filter increases the ratio $\left|Z / Z_{R}\right|$ for all the frequencies, compared to the values obtained without it. This means that no harmonic current will flow into the mains at all the resonant frequencies [11].

\section{OPTIMIZATION PACKAGE, OBJECTIVES AND CONSTRAINTS}

FORTRAN feasible sequential quadratic programming (FFSQP) is selected as an optimization technique because of its several advantages. It is very simple, especially if the designer was aware with FORTRAN codes. It is capable of attaining reasonable solution accuracy and granting speedy convergence to the best global and/or near global solution, in solving constrained nonlinear optimization problems. What differentiates this algorithm from conventional algorithms is the fewer computations required to generate a new iteration while having the benefit of the global and fast local convergence properties [1], [20], [21].

The following objective functions are considered in the optimal sizing of the HPF: 
Objective 1: Minimizing the total voltage harmonic distortion VTHD at the compensated load terminals given as

$\mathrm{VTHD}=\frac{\sqrt{\sum_{\mathrm{n}>1} \mathrm{~V}_{\mathrm{Ln}}^{2}}}{\mathrm{~V}_{\mathrm{L} 1}}$

Objective 2: Maximizing the load power factor $P F$ given as

$\mathrm{PF}=\frac{\mathrm{P}_{\mathrm{L}}}{\mathrm{V}_{\mathrm{L}} \mathrm{I}_{\mathrm{S}}}$

where, $P_{\mathrm{L}}$ represents the load active-power per-phase. The displacement power factor ( $\mathrm{dPF})$ is equals to the load power factor $(\mathrm{PF})$ at the fundamental frequency, i.e. $\mathrm{n}=1$.

Both objectives are unimodal functions. They are subjected to the following constraints:

1.Maintaining the $P F$ at a desired range (i.e. $90 \% \leq P F \leq 95 \%$ ).

2.According to IEEE Std. 519; VTHD should be limited at a specified range (i.e. $0 \% \leq V T H D \leq 5 \%$ ). Also, the individual voltage harmonic distortion IVHD should be at a specified range (i.e. $0 \% \leq I V H D \leq 3 \%$ ).

3.ITHD should be limited to a standard percent according to the system strength [16], where ITHD is given as

$\mathrm{ITHD}=\frac{\sqrt{\sum_{\mathrm{n} \succ 1} \mathrm{I}_{\mathrm{Sn}}^{2}}}{\mathrm{I}_{\mathrm{S} 1}}$

4. The HPF parameters $\left(X_{\mathrm{C}}, X_{\mathrm{P}}\right.$, and $\left.K\right)$ bounds are specified as follows

$0.00 \leq K \leq 20.00$

$0.00 \leq X_{\mathrm{C}} \leq 10.00$

$0.00 \leq X_{\mathrm{P}} \leq 1.00$

Summary of the proposed search algorithm is demonstrated below [1], [10] and [20]:

1.Prepare the nonlinear problem parameters, objectives and constraints while specifying the lower and upper bounds for each parameter.

2.Substitute the values of $X_{\mathrm{C}}, X_{\mathrm{P}}$ and $K$ into the objective functions, and calculate local minimums or maximums, whilst complying with the constraints.

3. Scan through the local minimums or maximums in order to ascertain the global solution.

4.Extract the required global output.

5.Determine the parameter sizing corresponding to the global solution.

\section{CASE STUDIES AND SIMULATED RESULTS}

Four cases of an exemplary industrial plant primary taken from [16] are shown in Table I. Two MVA (short-circuit capacity expressed in mega volt-amperes) system capacities are used in the study cases, where the
$80 \mathrm{MVA}_{\mathrm{SC}}$ is used in Cases 1 and 2, representing a weak system, whilst the $150 \mathrm{MVA}_{\mathrm{SC}}$ used in Cases 3 and 4 representing a stiff one. The three-phase active-power is $5100 \mathrm{~kW}$ and the three-phase inductive reactive-power is 4965 kvar. The 60-cycle supply voltage is $4160 \mathrm{~V}(2400$ volt line-to-neutral).

TABLE I

SYSTEM PARAMETERS, CONSIDERING HARMONIC CONTENTS OF THE SOURCE VOLTAGE AND THE LOAD CURRENT

\begin{tabular}{c|c|c|c|c}
\hline \hline Parameters \& Cases & Case 1 & Case 2 & Case 3 & Case 4 \\
\hline Short Circuit MVA & \multicolumn{2}{|c|}{80} & \multicolumn{2}{|c}{150} \\
\hline $\mathrm{V}_{\mathrm{S} 1}[\mathrm{kV}]$ & 2.40 & 2.40 & 2.40 & 2.40 \\
\hline $\mathrm{R}_{\mathrm{T}}[\Omega]$ & 0.0216 & 0.0216 & 0.0115 & 0.0115 \\
\hline $\mathrm{X}_{\mathrm{T}}[\Omega]$ & 0.2163 & 0.2163 & 0.1154 & 0.1154 \\
\hline $\mathrm{R}_{\mathrm{L}}[\Omega]$ & 1.7421 & 1.7421 & 1.7421 & 1.7421 \\
\hline $\mathrm{X}_{\mathrm{L}}[\Omega]$ & 1.6960 & 1.6960 & 1.6960 & 1.6960 \\
\hline $\mathrm{V}_{\mathrm{S} 5}\left[\% \mathrm{~V}_{\mathrm{S} 1}\right]$ & 3.00 & 3.00 & 3.00 & 3.00 \\
\hline $\mathrm{V}_{\mathrm{S} 7}\left[\% \mathrm{~V}_{\mathrm{S} 1}\right]$ & 2.00 & 2.00 & 2.00 & 2.00 \\
\hline $\mathrm{V}_{\mathrm{S} 11}\left[\% \mathrm{~V}_{\mathrm{S} 1}\right]$ & 1.00 & 1.00 & 1.00 & 1.00 \\
\hline $\mathrm{V}_{\mathrm{S} 13}\left[\% \mathrm{~V}_{\mathrm{S} 1}\right]$ & 0.50 & 0.50 & 0.50 & 0.50 \\
\hline $\mathrm{I}_{\mathrm{L} 5}\left[\% \mathrm{I}_{\mathrm{R}}\right]$ & 20.00 & 40.00 & 20.00 & 40.00 \\
\hline $\mathrm{I}_{\mathrm{L} 7}\left[\% \mathrm{I}_{\mathrm{R}}\right]$ & 14.00 & 14.00 & 14.00 & 14.00 \\
\hline $\mathrm{I}_{\mathrm{L} 11}\left[\% \mathrm{I}_{\mathrm{R}}\right]$ & 9.00 & 9.00 & 9.00 & 9.00 \\
\hline $\mathrm{I}_{\mathrm{L} 13}\left[\% \mathrm{I}_{\mathrm{R}}\right]$ & 7.50 & 7.50 & 7.50 & 7.50 \\
\hline \hline
\end{tabular}

Table II shows the uncompensated system results for the different case studies, to be defined and compared with the HPF results.

TABLE II

SIMULATED RESULTS OF THE INDUSTRIAL PLANT BEFORE COMPENSATION

\begin{tabular}{c|c|c|c|c}
\hline \hline Parameters \& Cases & Case 1 & Case 2 & Case 3 & Case 4 \\
\hline $\mathrm{PF}(\%)$ & 68.45 & 64.62 & 68.96 & 65.37 \\
\hline $\mathrm{dPF}(\%)$ & 71.65 & 71.65 & 71.65 & 71.65 \\
\hline $\mathrm{I}_{\mathrm{S}}(\mathrm{A})$ & 953.11 & 1000.91 & 984.85 & 1036.18 \\
\hline $\mathrm{V}_{\mathrm{L}}(\mathrm{V})$ & 2275.32 & 2298.97 & 2325.49 & 2332.80 \\
\hline $\mathrm{VTHD}(\%)$ & 17.03 & 22.47 & 9.77 & 12.61 \\
\hline $\mathrm{ITHD}(\%)$ & 25.96 & 42.08 & 26.53 & 42.99 \\
\hline \hline
\end{tabular}

Table III shows a summary of the results for the four case studies, Objective 1.

TABLE III

SIMULATED RESULTS OF THE PROPOSED HPF, OBJECTIVE 1

\begin{tabular}{c|r|c|c|c}
\hline \hline Parameters \& Cases & Case 1 & Case 2 & Case 3 & Case 4 \\
\hline $\mathrm{X}_{\mathrm{C}}(\Omega)$ & 6.9073 & 6.3486 & 6.8981 & 6.8763 \\
\hline $\mathrm{X}_{\mathrm{P}}(\mathrm{m} \Omega)$ & 0.0553 & 1.0516 & 0.0295 & 0.0813 \\
\hline $\mathrm{K}(\Omega)$ & 14.8401 & 16.9242 & 12.4018 & 14.8259 \\
\hline $\mathrm{PF}(\%)$ & 90.00 & 91.46 & 90.01 & 90.00 \\
\hline $\mathrm{dPF}(\%)$ & 90.07 & 91.57 & 90.10 & 90.15 \\
\hline $\mathrm{I}_{\mathrm{S}}(\mathrm{A})$ & 756.16 & 746.12 & 769.87 & 769.96 \\
\hline $\mathrm{V}_{\mathrm{L}}(\mathrm{V})$ & 2311.05 & 2316.97 & 2353.44 & 2353.40 \\
\hline $\mathrm{VTHD}(\%)$ & 2.79 & 2.47 & 3.14 & 2.91 \\
\hline $\mathrm{ITHD}(\%)$ & 2.88 & 4.17 & 3.39 & 5.00 \\
\hline \hline
\end{tabular}

Table IV shows a summary of the results for the four case studies, Objective 2. 
TABLE IV

SIMULATED RESULTS OF THE PROPOSED HPF, OBJECTIVE 2

\begin{tabular}{c|c|c|c|c}
\hline \hline Parameters & Case 1 & Case 2 & Case 3 & Case 4 \\
\hline $\mathrm{X}_{\mathrm{C}}(\Omega)$ & 5.3271 & 5.2948 & 5.4265 & 5.4382 \\
\hline $\mathrm{X}_{\mathrm{P}}(\mathrm{m} \Omega)$ & 85.0497 & 54.7369 & 193.9408 & 202.9380 \\
\hline $\mathrm{K}(\Omega)$ & 14.1699 & 16.8844 & 13.7073 & 16.6868 \\
\hline $\mathrm{PF}(\%)$ & 95.00 & 95.00 & 95.00 & 95.00 \\
\hline $\mathrm{dPF}(\%)$ & 95.07 & 95.08 & 95.09 & 95.09 \\
\hline $\mathrm{I}_{\mathrm{S}}(\mathrm{A})$ & 723.08 & 723.21 & 732.94 & 732.95 \\
\hline $\mathrm{V}_{\mathrm{L}}(\mathrm{V})$ & 2333.88 & 2333.52 & 2366.66 & 2366.59 \\
\hline $\mathrm{VTHD}(\%)$ & 3.66 & 3.17 & 4.21 & 4.16 \\
\hline $\mathrm{ITHD}(\%)$ & 1.64 & 2.68 & 2.40 & 2.10 \\
\hline \hline
\end{tabular}

Table III and Table IV show that the proposed HPF results in a notable reduction in the supply current value, VTHD percent and a significant reduction in the ITHD percent. Both VTHD and ITHD are complying with the IEEE Std. 519-1992 limits. It is evident that the gain value must be increased to satisfy the supply current compensation requirements, especially when the load is highly distorted (as shown in Cases 2 and 4). Besides, acceptable load power factor is observed in all cases under study compared to the uncompensated system cases shown in Table II.

Fig. (3). shows the harmonic signature of the supply current after compensation in Objective 1: Cases 1 and 2, while Fig. (4). shows them in Objective 1: Cases 3 and 4, respectively. Both are compared to the IEEE Std. 519 limits. The resultant values all come out well within the standard limits.

Fig. (5). shows the harmonic signature of the load voltage after compensation in Objective 2: Cases $\mathbf{1}$ and 2, while Fig. (6). shows them in Objective 2: Cases 3 and 4, respectively. Both are compared to the IEEE Std. 519 limits. Once more, it is obvious that the resultant values all come out well within standard limits.

From the previous figures and tables, it is obvious that the optimal filter design using Objective 2 is more satisfactory; it results in-higher $P F$ and lower harmonic signatures of $I_{\mathrm{S}}$ and $V_{\mathrm{L}}$, while maintaining the individual harmonic content of them compatible with the IEEE Std. 519 limits. At the same time, the gain is not significantly higher than the corresponding resultant values in the cases using Objective 1.

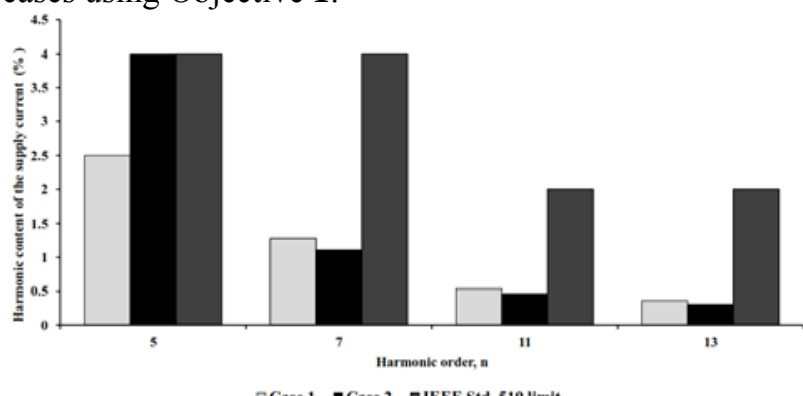

Fig. (3). Harmonic signature of the supply current, Objective 1: Cases 1 and 2

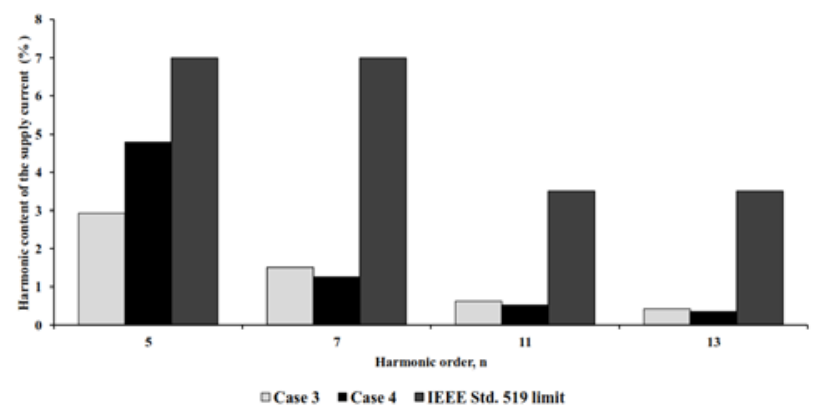

Fig. (4). Harmonic signature of the supply current, Objective 1: Cases 3 and 4

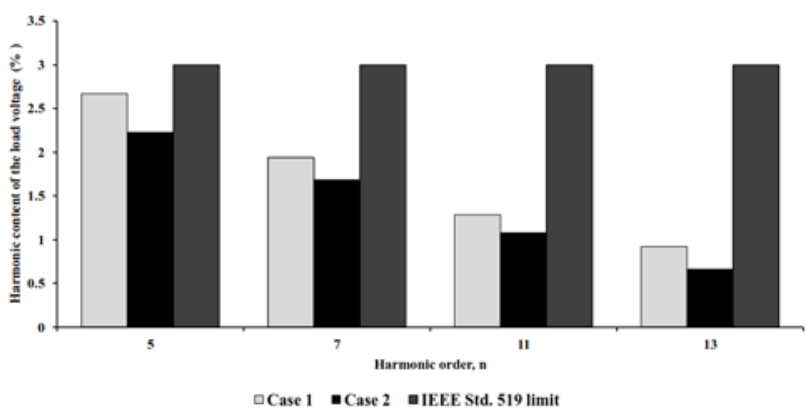

Fig. (5). Harmonic signature of the load voltage, Objective 2: Cases 1 and 2

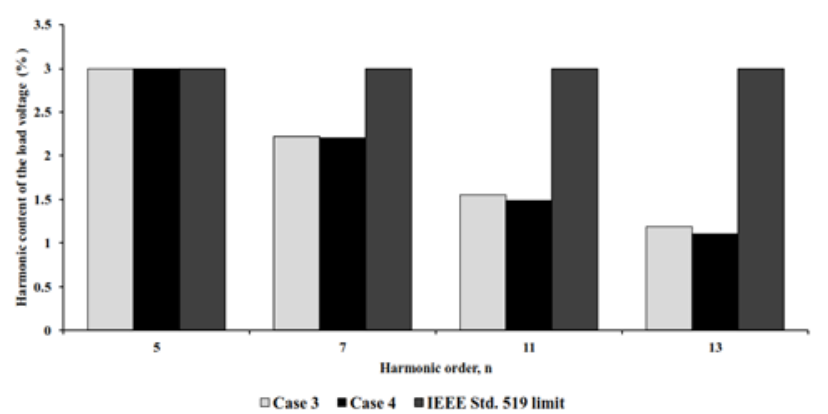

Fig. (6). Harmonic signature of the load voltage, Objective 2: Cases 3 and 4

Trading the VTHD as an objective function has a considerable effect on decreasing the voltage distortion at the load bus but can not suppress the proliferation of the harmonic currents. Consequently, in order to keep the same total harmonic distortion in supply currents; $K$ must be increased, especially in weak power systems, represented in Cases 1 and 2 [22].

The compensation performance of the HPF is extremely affected by the gain value $(K)$. Figures (7) - (9) show the effect of variation of $K$ on VTHD, ITHD and $P F$, respectively, in the nonlinear problem: Objective 2, Case 4. Roughly speaking, large values of $K(K>12)$ improve the hybrid active/passive filter compensation performance [10]. 


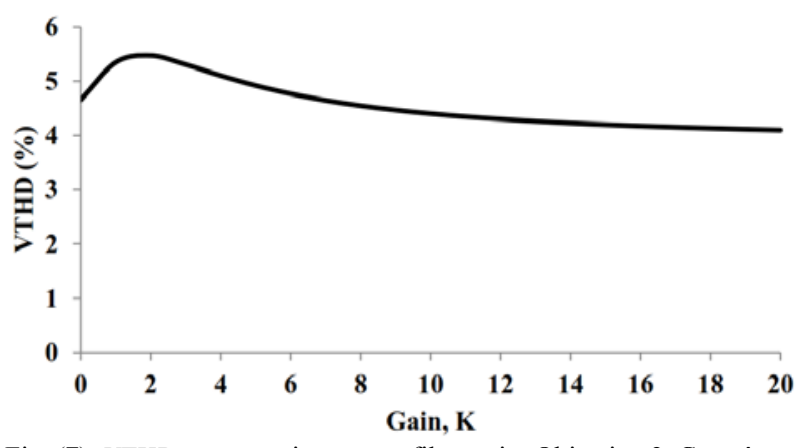

Fig. (7). VTHD versus active-power filter gain: Objective 2, Case 4

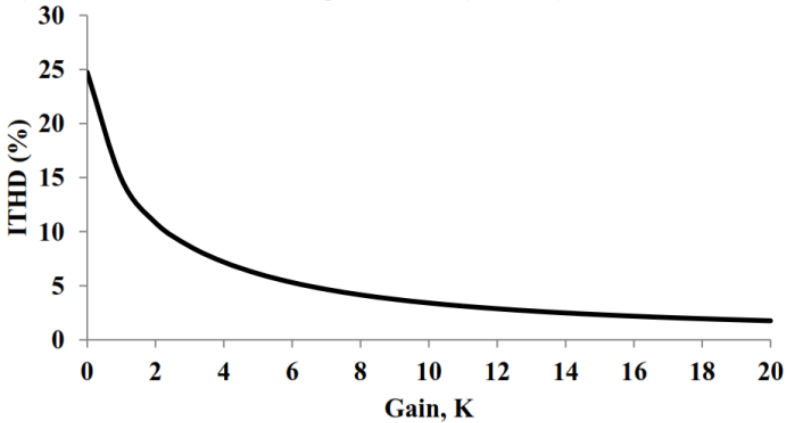

Fig. (8). ITHD versus active-power filter gain: Objective 2, Case 4

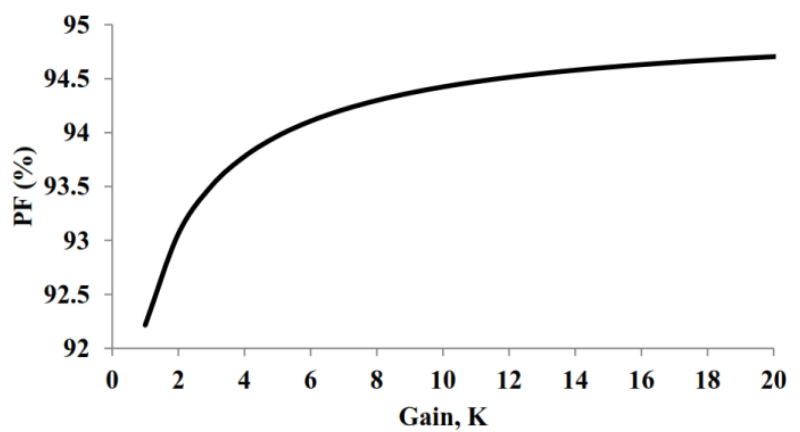

Fig. (9). $P F$ versus active-power filter gain: Objective 2, Case 4

Table $\mathbf{V}$ shows the frequency responses of the attenuation factor and ratio of $\left|Z / Z_{R}\right|$ before and after compensation (i.e. $K=0$ and $K=16.69$ ) in the nonlinear problem: Objective 2, Case 4. It is evident that larger values of $K$ improves the attenuation of current harmonics and decreases the peak of the attenuation factor, thus increases the passive filter bandwidth, decreases the impedance at the resonant frequency and eliminate the possibility of parallel resonance initiation. Moreover, the HPF increases the ratio of $\left|Z / Z_{R}\right|$ for all the frequencies compared to values obtained without it. Therefore, no harmonic current will flow into the mains at the resonant frequencies. In other words, series and parallel resonances have no chance to occur.

Ref. [13] demonstrates that it is easier to compensate current harmonics in weak power systems (low value of $\mathrm{MVA}_{\mathrm{SC}}$ ) than in stiff systems (high value of MVA $\mathrm{A}_{\mathrm{SC}}$ ). In other words, if $\mathrm{MVA}_{\mathrm{SC}}$ increases, ITHD increases, as shown in Table II. As a normal reaction; the hybrid power filter gain must be increased. However, this is valid only under the assumption of $V_{\mathrm{Sn}}$ equals zero (ideal source). Table III and Table IV show that this is not valid, while considering the source harmonic voltages $V_{S n}$. Therefore, it is necessary to state the change in the VTHD and ITHD with $K$ to guarantee better compensation performance of the hybrid scheme.

TABLE V

SIMULATED RESULTS OF THE ATTENUATION FACTOR AND RATIOS OF $\left|Z / Z_{\mathrm{R}}\right|:$ Objective $\mathbf{2}$, Case 4

\begin{tabular}{c|c|c|c|c}
\hline \hline \multirow{2}{*}{ Harmonic number (n) } & \multicolumn{2}{|c|}{$\mid \mathrm{AF}$} & \multicolumn{2}{c}{$\mid \mathrm{Z} / \mathrm{Z}_{\mathrm{R}}$} \\
\cline { 2 - 5 } & $K=0$ & $K=16.69$ & $K=0$ & $K=16.69$ \\
\hline 1 & 0.9852 & 0.9852 & 1.347 & 1.347 \\
\hline 2 & 1.0461 & 0.1368 & 1.6925 & 12.9384 \\
\hline 3 & 1.291 & 0.0719 & 0.4846 & 8.7035 \\
\hline 4 & 4.4509 & 0.0328 & 0.0548 & 7.4344 \\
\hline 5 & 0.1461 & 0.0044 & 0.2071 & 6.9298 \\
\hline 6 & 0.3039 & 0.0186 & 0.4091 & 6.6822 \\
\hline 7 & 0.4308 & 0.0384 & 0.5836 & 6.5467 \\
\hline 8 & 0.489 & 0.0562 & 0.7429 & 6.4691 \\
\hline 9 & 0.5217 & 0.0725 & 0.8929 & 6.425 \\
\hline 10 & 0.5423 & 0.0878 & 1.0368 & 6.4021 \\
\hline 11 & 0.5563 & 0.1023 & 1.1763 & 6.3937 \\
\hline 12 & 0.5662 & 0.1162 & 1.3128 & 6.3958 \\
\hline 13 & 0.5736 & 0.1296 & 1.4468 & 6.4058 \\
\hline \hline
\end{tabular}

\section{CONCLUSIONS}

The article analyzes the optimal design of the HPF, taking into account individual voltage and current distortion limits. The filter design problem was formulated as a nonlinear problem and was solved using the FFSQP package. The proposed filter suppresses voltage and current harmonic distortion, with no resonance possibility with source and/or load. Four cases are tested, and the general act of the proposed technique is satisfactory.

The results show that there is a swap in the power converter gain values between minimizing the voltage and current harmonic distortion in the presence of source voltage harmonics. Based on the presented results and analysis, it is important to take the source voltage harmonics into account when designing passive or hybrid filters. Thus, analysis, evaluation and comparison of different hybrid power filter connections, including their topologies and ratings will be taken into account, while considering source and load nonlinearities, using the FFSQP algorithm as an optimization method. Furthermore, the design objectives may include the previous objective functions cooperated with other conflicted objectives and constraints.

\section{Acknowledgments:}

The authors gratefully acknowledge and thank Jian L. Zhou, Andre L. Tits and Craig T. Lawrence who provided the FFSQP package.

\section{REFERENCES}

[1] S. H. E. Abdel Aleem, A. F. Zobaa and M. M. Abdel Aziz, "Optimal C-type passive filter based on minimization of the voltage harmonic distortion for nonlinear loads," IEEE Trans. Ind. Electron., vol. 59, no.1, pp. 281-289, Jan. 2012. 
[2] Jafaboland Mehrdad. (2011, March-April). Time Domain Analysis of Fourth Order LCLC Resonant Converter. Int. Rev. of Elect. Eng., IREE 6(2A), pp. 459-466.

[3] Perttu Parkatti, Heikki Tuusa, Hannu Sarén, Kosti Kuusela and Michael Björkman. (2011, March-April). Analysis and Performance of a High-Efficiency Transformerless Hybrid Active Filter. Int. Rev. of Elect. Eng., IREE 6(2A), pp. 537546 .

[4] M. B. M. Rozlan, A. F. Zobaa and S. H. E. Abdel Aleem. (2011, Aug.). The Optimisation of Stand-Alone Hybrid Renewable Energy Systems Using HOMER. Int. Rev. of Elect. Eng., IREE 6(4B), pp. 1802-1810.

[5] Masoud Farhoodnea, Azah Mohamed, Hussain Shareef and Hadi Zayandehroodi. (2012, Apr.). Localization of Multiple Harmonic Sources in Non-Radial Power Distribution Systems. Int. Rev. of Elect. Eng., IREE 7(2B), pp. 4134-4145.

[6] S. H. E. Abdel Aleem, A. F. Zobaa, and A. C. M. Sung, "On the economical design of multiple-arm passive harmonic filters," in 47th International Universities' Power Engineering. Conf., UPEC'12, Uxbridge, Middlesex, United Kingdom, Sep. 4-7, 2012, pp. 1-6.

[7] H. L. Jou, J. C. Wu, K. D. Wu, M. S. Huang, and C. A. Lin. (2006, Sep.). A Hybrid Compensation System Comprising Hybrid Power Filter and AC Power Capacitor. Electr. Pow. Energy Sys. Journal 28(7), pp. 448-458.

[8] A. Khanjanzadeh, M. Sedighizadeh, A. Rezazadeh and A. Pahlavanhoseini. (2011, Jun.). Using Clonal Selection Algorithm for Sitting and Sizing of Distributed Generation in Distribution Network to Improve Voltage Profile and Reduce THD and Losses. Int. Rev. of Elect. Eng., IREE 6(3B), pp. 1325-1331.

[9] Purwoharjono, Muhammad Abdillah, Ontoseno Penangsang and Adi Soeprijanto. (2013, Feb.). Optimal Placement of SVC for Losses Reduction and Voltage Profile Improvement in Electrical Power System Using Improved Gravitational Search Algorithm. Int. Rev. of Elect. Eng., IREE 8(1B), pp. 329-339.

[10] A. F. Zobaa, "Optimal Multiobjective Design of Hybrid active Power Filters Considering Distorted Environments," IEEE Trans. Ind. Electron., vol. 61, no.1, pp. 107-114, Jan. 2014.

[11] F. Z. Peng, H. Akagi, and A. Nabae, "A New Approach to Harmonic Compensation in Power Systems - A Combined System of Shunt Passive and Series Active Filters," IEEE Trans. Ind. Applications, vol. 26, no. 6, pp. 983-990, Nov./Dec. 1990

[12] P. Jintakosonwit, H. Fujita, H. Akagi and S. Ogasawara "Implementation and Performance of Cooperative Control of Shunt Active Filters for Harmonic Damping Throughout a Power Distribution System," IEEE Trans. Ind. Appl., vol. 39, no. 2, pp. 556-564, Mar./Apr. 2003.

[13] L. Chen and A. V. Jouanne, "A Comparison and Assessment of Hybrid Filter Topologies and Control Algorithms," in 32nd Power Electronics Specialists Conf., PESC'01, Vancouver, Canada, Jun. 17-21, 2001, pp. 565-570.

[14] Giovanni Mazzanti. (2011, Nov.). Are the Limits to Harmonic Voltages Given by International Standards on the Safe Side from the Viewpoint of Power Component Reliability?. Int. Rev. of Elect. Eng., IREE 6(6), pp. 2762-2772.

[15] J. Zhang, "Hybrid Conditioner for a Power System," U. S. Patent 20110057517, March 10, 2010.

[16] IEEE Recommended Practices and Requirements for Harmonic Control in Electrical Power Systems, IEEE Standard 5191992, 1992.

[17] A. F. Zobaa, M. M. Abdel-Aziz and S. H. E. Abdel Aleem. (2010, Mar.). Comparison of shunt-passive and series-passive filters for DC drives loads. Electr. Pow. Compo. Sys. 38(3), pp. 275-291.

[18] S. H. E. Abdel Aleem and A. F. Zobaa. (2013, Jan.) Different Design Approaches of Shunt Passive Harmonic Filters Based on IEEE Std. 519-1992 and IEEE Std. 18-2002. Recent Pat. Elec. Eng. 6(1), pp. 68-75.

[19] H. H. Zeineldin and A. F. Zobaa. (2011, Oct.). Particle Swarm Optimization of Passive Filters for Industrial Plants in Distribution Networks. Electr. Pow. Compo. Sys. 39(16), pp. 1795-1808.
[20] J. L. Zhou, A. L. Tits, and C. T. Lawrence, User's guide for FFSQP version 3.7: A FORTRAN code for solving optimization problems, possibly minimax, with general inequality constraints and linear equality constraints, generating feasible iterates, TR-92-107r5, Institute for Systems Research, University of Maryland, College Park, MD20742, USA, 1997.

[21] A. F. Zobaa and S. H. E. Abdel Aleem, “A New Approach for Harmonic Distortion Minimization in Power Systems Supplying Nonlinear Loads," IEEE Trans. on Ind. Informatics., in press.

[22] M. T. Elmathana, A. F. Zobaa and S. H. E. Abdel Aleem, "Economical design of multiple-arm passive harmonic filters for an industrial firm - case study," $15^{\text {th }}$ International Conference on Harmonics and Quality of Power, ICHQP 2012, Hong Kong, June 17-20, 2012. Paper ID: 0103.

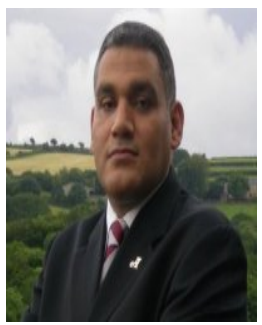

Ahmed Faheem Zobaa received the B.Sc.(Hons.), M.Sc., and Ph.D. degrees in electrical power and machines from Cairo University, Giza, Egypt, in 1992, 1997, and 2002, respectively. From 2007 to 2010, he was a Senior Lecturer in renewable energy with the University of Exeter, Cornwall, U.K. He was also an Instructor from 1992 to 1997, a Teaching Assistant from 1997 to 2002, an Assistant Professor from 2003 to 2008, and an Associate Professor from 2008 to 2012 with the Department of Electrical Power and Machines and the Faculty of Engineering, Cairo University, where he has also been a Professor since December 2012. Currently, he is also a Senior Lecturer in power systems with Brunel University, London, U.K. His main areas of expertise are lighting applications, power quality, (marine) renewable energy systems, grid integration, smart grids and energy management.

Dr. Zobaa is an Editor-in-Chief for the International Journal of Renewable Energy Technology. He is also an Editorial Board member, Editor, Associate Editor, and Editorial Advisory Board member for many international journals. $\mathrm{He}$ is a registered Chartered Engineer, Chartered Energy Engineer, European Engineer, and International Professional Engineer. $\mathrm{He}$ is also a registered member of the Engineering Council U.K., Egypt Syndicate of Engineers, and the Egyptian Society of Engineers. He is a Fellow of the Institution of Engineering and Technology, the Energy Institute of U.K., the Chartered Institution of Building Services Engineers, the Royal Soiety of Arts, and the Higher Education Academy of U.K. He is a senior member of the Institute of Electrical and Electronics Engineers. He is a member of the International Solar Energy Society, the European Society for Engineering Education, the European Power Electronics and Drives Association, the British Institute of Energy Economics, and the IEEE Standards Association.

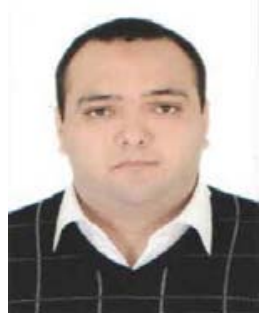

Khaled Elmathana was born in United Arab of Emirates in 1985. He received his B.Sc. in Electronics Engineering from the German University in Cairo, Egypt in 2008. He is currently a Ph.D. student at Brunel University, United Kingdom. His research area is power quality. 